\title{
Pengaruh Model Pembelajaran Direct Instruction Terhadap Keterampilan Tata Boga Anak Tunarungu
}

\author{
Fitri Rahma Utari $^{1}$, Marlina Marlina ${ }^{2}$, Kasiyati Kasiyati ${ }^{3}$ \\ ${ }^{123}$ Universitas Negeri Padang, Indonesia \\ Email: fitrirahmautari@gmail.com
}

\section{INFORMASI ARTIKEL}

Terkirim 28 Maret 2019

Revisi 27 Juli 2019

Diterima 02 Maret 2020

Kata kunci:

model pembelajaran direct instruction, keterampilan tata boga, tunarungu.

\begin{abstract}
ABSTRAK
Permasalahan yang ditemukan dalam bidang keterampilan tata boga di SLB Perwari Padang yaitu kurangnya variasi dalam membuat olahan berbagai makanan dan minuman, metode yang digunakan guru kurang bervariasi. Tujuan penelitian untuk membuktikan bahwa model pembelajaran direct instruction efektif dalam meningkatkan keterampilan tata boga membuat cokelat aneka bentuk pada anak tunarungu terutama kelas V di SLB Perwari Padang. Penelitian ini menggunakan metode eksperimen, desain pre-eksperimental dengan dua kali observasi yaitu sebelum dan sesudah eksperimen. Data dikumpulkan dengan tes melalui kisi-kisi instrumen yang diuji menggunakan uji mann withney. Subjek penelitian yaitu empat orang siswa. Hasil penelitian menunjukkan: 1) proses pembelajaran keterampilan tata boga membuat cokelat aneka bentuk dilakukan menggunakan model pembelajaran direct instruction. 2) hasil keterampilan tata boga membuat cokelat aneka bentuk anak tunarungu kelas $\mathrm{V}$ meningkat melalui model pembelajaran direct instruction. Maka disimpulkan model pembelajaran direct instruction efektif dalam meningkatkan keterampilan tata boga anak tunarungu kelas V di SLB Perwari Padang.
\end{abstract}

is is an open access article distributed under the Creative Commons 4.0 Attribution License, This license lets others remix, tweak, and build upon your work even for commerci purposes, as long as they credit you and license their new creations under the identical terms $\odot 2018$ by author and Universitas Negeri Padang.

Pendahuluan

Pembelajaran keterampilan telah diajarkan di sekolah, termasuk bagi anak berkebutuhan khusus. Pendidikan bagi anak berkebutuhan khusus baik di sekolah reguler dan sekolah luar biasa, hakekatnya untuk membantu anak mengembangkan potensinya, tujuan pembelajaran keterampilan tersebut untuk membekali ABK agar memiliki keterampilan kerja yang bermanfaat pasca sekolah (Ishartiwi, 2010). Kecakapan hidup atau life skill merupakan suatu modal utama dalam mencapai kemadirian hidup seseorang. Selain itu berkaitan dengan peran penting psikologi pendidikan adalah bagaimana membelajarkan semua anak dengan menyenangkan, memperhatikan perbedaan individual semua anak, membelajarkan anak berdasarkan prinsip-prinsip psikologi belajar (Marlina, 2014).

Kecakapan hidup berkaitan dengan keterampilan disekolah, keterampilan yang produktif merupakan keterampilan yang menghasilkan atau memiliki nilai harga. Pembelajaran keterampilan sangat penting dipelajari oleh anak agar nantinya dapat digunakan dan dikembangkan dikemudian hari, salah satunya anak berkebutuhan khusus yaitu anak tunarungu yang banyak menonjolkan keterampilan. Melalui pembelajaran keterampilan, anak tunarungu dapat mengasah kelebihan dengan mengembangkan keterampilan yang di pelajarinya. Untuk mencapai hasil belajar keterampilan bagi ABK latihan berualngulang sampai menjadikan kebiasaan dalam hidup. Jenis keterampilan disesuaikan dengan bakat dan minat ABK. Cakupan bahan ajar minimal meliputi kemampuan menolong diri atau kegiatan hidup sehari-hari, keterampilan bersosialisasai atau bernasayarakat dilingkungan temapt tinggal dan keterampilan untuk bekerja. Semua keterampilan yang diajarkan tersebut dilaksanakan agar anak tunarungu dapat mandiri walaupun memiliki kekurangan di indera pendengarannya. Di dalam kurikulum tingkat satuan pendidikan (KTSP) mata pelajaran Seni Budaya dan Keterampilan (SBK) bagi ABK, bahwa kompetensi pembelajaran keterampilan mengarah kepada jenis keterampilan vokasional sama dengan kurikulum SBK di sekolah reguler antara lain: tata boga, tata busana, pertukangan kayu, pertanian, peternakan, otomotif, jasa, musik, tari tradisional dan modern serta keterampilan berbasis teknologi tinggi (Ishartiwi, 2010).

Keterampilan tata boga merupakan salah satu mata pelajaran untuk meningkatkan keterampilan peserta didik yang berfokus pada pengelolaan, pembuatan, dan penyajian makanan (Yuly, Hartaty 2017). Proses pembalajaran tata boga menuntut anak untuk kreatif dalam mengolah bahan mentah menjadi makanan yang memiliki rasa yang lezat dan bergizi,

Jurnal Pendidikan Kebutuhan Khusus

21 
serta memiliki varian rasa yang berbeda-beda sehingga memiliki nilai jual yang tinggi. Keterampilan di bidang tata boga memiliki banyak variasi dan teknik, di antaranya teknik memasak basah yang di dalamnya terdapat teknik mengetim. Teknik mengetim digunakan salah satunya untuk mengetim nasi dan melelehkan cokelat (Rosilawati,Ina 2013:117).

Berdasarkan hasil studi pendahuluan yang peneliti lakukan di SLB Perwari Padang di kelas V/B terdapat empat orang anak tunarungu. dua orang wanita dan dua laki-laki. Saat melakukan observasi di kelas tersebut guru menggunakan KTSP. di dalam kelas peneliti mengamati bahwa guru telah mengajarkan berbagai keterampilan yang dapat mengembangkan keterampilan muridnya, seperti menjahit, menyulam, merangkai bunga atau pun memasak makanan tradisonal. Dibidang memasak guru telah mengajarkan membuat kue dari olahan ubi dan juga membuat puding, guru juga mengajarkan berbagai aneka minuman. Cara guru dalam mengajarkan anak dalam bidang tata boga melalui ceramah atau demonstrasi. Kreasi dalam bidang tata boga masih kurang, sehingga terdapat kejenuhan bagi anak dalam melaksanakan pembelajaran keterampilan terutama bidang tata boga, hasil dari wawancara dengan guru, membuat cokelat aneka bentuk belum pernah diajarkan di sekolah tersebut. Oleh karena itu, peneliti melakukan observasi awal mengenai membuat cokelat aneka bentuk pada anak tunarungu di kelas V/B.

Saat melakukan pre test awal membuat kreasi cokelat aneka bentuk, empat orang anak tersebut belum mengerti sama sekali cara membuat kreasi cokelat aneka bentuk tersebut. Anak-anak tersebut sangat antusias melihat beraneka warna cokelat yang peneliti bawa. Saat mempraktekan keterampilan tersebut anak masih belum tau langkah-langkah dalam membuat kreasi cokelat aneka bentuk tersebut, selalu bertanya kepada guru dan meminta bantuan dalam prosesnya. Kemampuan awal membuat kreasi cokelat aneka bentuk anak setelah dilakukan tes perbuatan sesuai dengan instrumen didapat masih rendah. Kemampuan awal membuat kreasi cokelat aneka bentuk anak setelah dilakukan tes perbuatan yaitu anak W mendapatkan skor 41,3\%, anak $\mathrm{N}$ mendapatkan skor 36,9\%, anak $\mathrm{T}$ mendapatkan skor $28,2 \%$, dan anak $\mathrm{A}$ mendapatkan skor $36,9 \%$.

Dari permasalahan tersebut, peneliti mengajarkan keterampilan dibidang keterampilan tata boga yaitu kreasi membuat cokelat aneka bentuk. Dimana cokelat banyak disukai anak. Rata-rata semua anak sangat menyukai cokelat apalagi dengan beraneka bentuk dan warna yang menarik. Selain itu keterampilan ini agar dapat menarik perhatian anak tunarungu, karena membuat anak lebih kreatif dan imajinatif serta memiliki nilai jual. Dan keterampilan di bidang tata boga membuat cokelat belum pernah di ajarkan oleh guru terutama di kelas tersebut. Berdasarkan hal tersebut maka peneliti mengajarkan anak tunarungu membuat cokelat aneka bentuk menggunakan model pembelajaran direct instruction. Dalam penelitian ini model pembelajaran direct instruction melalui pengetahuan secara prosedural maka guru berperan sebagai contoh dalam memberikan petunjuk-petunjuk dalam pembuatan cokelat aneka bentuk melalui sintack. Sintaks dapat digunakan dalam menjelaskan suatu pembelajaran baru melalui langkah-langkah yang sistematis (I Gusti Ngurah Agung Wijaya Mahardika, 2017). Dalam model pembelajaran direct instruction guru tidak terlalu banyak menjelaskan tetapi memperagakan selangkah demi selangkah caranya sehingga anak dapat memahami tahap demi tahap pembuatannya. Jadi menurut peneliti model pembelajaran direct instruction dapat digunakan untuk mengajarkan anak tunarungu dalam bidang keterampilan tata boga membuat cokelat aneka bentuk karena dengan model ini anak dapat lebih memahami proses pembuatan tahap demi tahap yang dilakukan secara prosedural.

\section{Metode}

\section{Jenis penelitian}

Jenis penelitian yang digunakan adalah metode eksperimen. Penelitian ini menggunakan pre-experimental design atau sering disebut dengan quasi experiment dengan jenis one group pretest-postest design (Arikunto, 2010:123). Observasi dilakukan sebanyak dua kali yaitu sebelum eksperimen dan setelah eksperimen. Observasi yang dilakukan sebelum eksperimen (01) disebut pretest, dan observasi sesudah eksperimen (02) disebut posttest, (Arikunto, 2006: 85) Metode ini digunakan untuk mengetahui apakah keterampilan tata boga membuat cokelat aneka bentuk meningkat melalui model pembelajaran direct instruction bagi anak tunarungu di kelas V SLB Perwari Padang.

Subjek penelitian

Subjek penelitian di SLB Perwari yaitu kelas V/B padang dapat dilihat dalam tabel berikut :

Tabel 1. . Subjek Penelitian Anak kelas V SLB Perwari Padang

\begin{tabular}{lllll}
\hline No & Kode nama & Kelas & Jenis kelamin & Umur \\
\hline 1 & \multicolumn{2}{c}{$\mathrm{T}$} & $\mathrm{V}$ & $\mathrm{P}$ \\
13 tahun & & & \\
\hline
\end{tabular}




\begin{tabular}{llll}
\hline 2 & W & V & L \\
14 tahun & & V & P \\
3 & N & & \\
13 tahun & & V & L \\
4 & A & & \\
\hline tahun & & 4 Orang & \\
\hline
\end{tabular}

Teknik pengumpulan data

Teknik pengumpulan data yang digunakan adalah dengan pemberian tes dengan mencatat hasil kegiatan yang dilakukan dan menghitung keberhasilan anak dengan benar dari kriteria atau kisi-kisi instrumen yang telah ditentukan (Sugiyono, 2014: 222-223) Sebelum diberikan perlakuan, kelompok diberikan pretest setelah itu diberikan perlakuan dan barulah diberikan posttest. Sehingga akan terlihat perbandingannya sebelum diberikan perlakuan dengan setelah diberikan perlakuan.. Lalu di uji menggunakan uji mann withney.

\section{Hasil Penelitian dan Pembahasan}

\section{Hasil Penelitian}

Dari hasil pretest dan posttest yang telah dilakukan, Kemampuan penguasaan siswa dalam membuat cokelat aneka bentuk terdiri dari langkah-langkah Dapat dilihat bahwa setelah diberikan perlakuan menggunakan model pembelajaran direct instruction terdapat peningkatan pada kemampuan membuat cokelat aneka bentuk. Yang dapat dilihat pada tabel berikut :

Tabel 2. Perbedaan Skor Pretest dan Posttest Anak Kelas V dalam Membuat cokelat aneka bentuk di SLB Perwari Padang

\begin{tabular}{|c|c|c|c|c|}
\hline No & Subjek Penelitian & Skor Pretest & Skor Posttest & Gain skor \\
\hline 1 & $\mathrm{~T}$ & 58,6 & 74 & 15,4 \\
\hline 2 & $\mathrm{~N}$ & 56,7 & 73 & 16,3 \\
\hline 3 & $\mathrm{~W}$ & 75,6 & 90 & 14,4 \\
\hline \multirow[t]{2}{*}{4} & $\mathrm{~A}$ & 63 & 90 & 27 \\
\hline & Rata-rata & 63,5 & 81,75 & \\
\hline
\end{tabular}

Selanjutnya menentukan peringkat dari masing- masing subjek penelitian sebelum diberikan perlakuan (X1), dan setelah diberikan perlakuan (X2) yang dapat dilihat dalam tabel berikut :

Tabel 5. Data Persiapan Menghitung Rank Anak dalam Membuat cokelat aneka bentuk di SLB Perwari Padang

\begin{tabular}{cccc}
\hline NO & Subject Penelitian & Nilai Skor & Rank \\
\hline 1 & W & 90 & 1,5 \\
2 & A & 90 & 1,5 \\
3 & W & 75,6 & 3 \\
4 & T & 74 & 4 \\
5 & N & 73 & 5
\end{tabular}

Jurnal Pendidikan Kebutuhan Khusus 


\begin{tabular}{llcl}
\hline 6 & A & 63 & 6 \\
7 & T & 58,6 & 7 \\
8 & N & 56,7 & 8
\end{tabular}

Lalu dianalisis dengan menggunakan rumus uji Mann Whitney. Adapun Hasil rank nilai dalam kemampuan keterampilan tata boga membuat cokelat aneka bentuk sebagai berikut:

Tabel 3. Data Keseluruhan dari Pretest dan Posttest serta Rank Anak Kelas V dalam Membuat Cokelat Aneka Bentuk di SLB perwari Padang

\begin{tabular}{cccccc}
\hline No & Subjek Penelitian & Nilai & Rank & Nilai & Rank \\
& & Pretest & $(\mathrm{R} 1)$ & Posttest & (R2) \\
\hline 1 & $\mathrm{~T}$ & 58,6 & 7 & 74 & 4 \\
2 & $\mathrm{~N}$ & 56,7 & 8 & 73 & 5 \\
3 & $\mathrm{~W}$ & 75,6 & 3 & 90 & 1,5 \\
4 & $\mathrm{~A}$ & 62,5 & 6 & 90 & 1,5 \\
& Rata-rata & 63,35 & 24 & 81,75 & 12
\end{tabular}

Setelah dilakukan pengolahan data maka didapat angka yang akan diolah menggunakan rumus uji Mann Whitney sebagai berikut :

$$
\begin{aligned}
& \mathrm{U}_{1}=\mathrm{n}_{1} \cdot \mathrm{n}_{2}+\frac{\mathrm{n}_{2}\left(\mathrm{n}_{2}+1\right)}{2}-\sum \mathrm{R}_{2} \\
& \mathrm{U}_{1}=4.4+\frac{4(4+1)}{2}-12 \\
& \mathrm{U}_{1}=16+\frac{20}{2}-12 \\
& \mathrm{U}_{1}=16-2 \\
& \mathrm{U}_{1}=\mathbf{1 4} \\
& \mathrm{U}_{2}=\mathrm{n}_{1} \cdot \mathrm{n}_{2}+\frac{\mathrm{n}_{1}\left(\mathrm{n}_{1}+1\right)}{2}-\sum \mathrm{R}_{1} \\
& \mathrm{U}_{2}=4.4+\frac{4(4+1)}{2}-24 \\
& \mathrm{U}_{2}=16+\frac{20}{2}-24 \\
& \mathrm{U}_{2}=16+10-24 \\
& \mathrm{U}_{2}=26-24 \\
& \mathbf{U}_{2}=\mathbf{2}
\end{aligned}
$$

Dari hasil perhitungan diatas maka didapat $U_{\text {hit }}=2$ yang diambil berdasarkan nilai hitung terkecil, selanjutnya disesuaikan pada taraf signifikan $95 \%$ dan $\alpha=0,05$ untuk $\mathrm{n}=4$ diperoleh $\mathrm{U}_{\text {tab }}=1$. Berdasarkan pengujian hipotesis menurut Nazir 
(2011:406) " $\mathrm{H}_{\mathrm{a}}$ diterima jika $\mathrm{U}_{\text {hit }}>\mathrm{U}_{\text {tab }}$ dan $\mathrm{H}_{0}$ ditolak jika $\mathrm{U}_{\text {hit }} \leq \mathrm{U}_{\text {tab }}$ ". Dalam keterampilan tata boga membuat cokelat aneka bentuk didapat $\mathrm{U}_{\text {hit }}>\mathrm{U}_{\text {tab }}$ dengan demikian $\mathrm{H}_{\mathrm{o}}$ ditolak dan $\mathrm{H}_{\mathrm{a}}$ diterima. Jadi dapat disimpulkan bahwa model pembelajaran direct instruction dapat meningkatkan keterampilan tata boga membuat cokelat aneka bentuk bagi anak tunarungu kelas V di SLB Perwari Padang.

\section{Pembahasan}

Berdasarkan hasil penelitian yang telah dilakukan perbandingan dari rata-rata nilai dan persentasi kemampuan masingmasing anak pada saat pretest dan posttest terlihat perbandingan yang meningkat terhadap kemampuan membuat cokelat aneka bentuk setelah diberikan perlakuan dengan model pembelajaran Direct instruction. Model pembelajaran direct instruction dapat diterapkan bagi anak berkebutuhan khusus sama hal nya dengan pendapat oleh I Gusti Ngurah Agung Wijaya Mahardika (2017) yang mengatakan bahwa model pembelajaran direct instruction dapat digunakan di SLB bagi anak tunanetra dalam proses pembelajarannya menggunakan sintaks model pembelajaran langsung dengan digabungkan dengan model pengajaran nondirektif. Jadi model pembelajaran direct instruction dapat digunakan termasuk dalam menyampaikan pembelajaran tata boga.

Pembelajaran tata boga perlu diajarkan bagi anak berkebutuhan khusus, termasuk anak tunarungu. Dimana keterampilan tata boga menunjang untuk anak lebih mandiri, mengenal banyak jenis keterampilan dalam bidang tata boga nantinya, dalam menyajikan materi mengenai keterampilan tata boga sangat bervariasi sama dengan pendapat Yuli Hartaty (2017) yang mengatakan terlihat adanya peningkatan hasil belajar keterampilan tataboga materi pembuatan brownis pisang pada peserta didik kelas XII SMALB - C Negeri Metro dengan menggunakan model eksplicit instruction, Dimana anak tunagrahita tersebut dapat mengembangkan keterampilannya dibidang tata boga. Selain itu di dalam kurikulum tingkat satuan pendidikan (KTSP) tahun 2007 untuk mata pelajaran Seni Budaya dan Keterampilan (SBK) bagi ABK mengatakan bahwa kompetensi pembelajaran keterampilan mengarah kepada jenis keterampilan vokasional sama dengan kurikulum SBK di sekolah reguler salah satunya termasuk pembelajaran tata boga (Ishartiwi, 2010).

Selain itu ada dampak lain yang ditimbulkan dalam penelitian ini adalah membuat anak lebih kreatif mengembangkan imajinasinya, memadukan warna kebentuk cetakan cokelat yang ada. Selain itu dalam proses pembelajaran anak antusias dalam mengikuti setiap langkah-langkah pembelajaran yang dijelaskan. Sama halnya dengan penelitian Sihono dan Rahma (2012) yang mengatakan kreativitas pada siswa dapat menghasilkan prestasi belajar yang berdampak bagi siswa tersebut untuk menjadi pribadi yang mandiri sehingga dapat dikatakan bahwa kreativitas siswa mempengaruhi kemandirian siswa.

\section{Kesimpulan}

Berdasarkan permasalahan yang diteliti, yaitu model pembelajaran direct instruction dalam meningkatkan keterampilan membuat cokelat aneka bentuk kelas V/B di SLB Perwari Padang. Hasil dari perhitungan data yang diolah menggunakan rumus uji $\mathrm{U}$ Mann Withney didapat $\mathrm{n}=4$ pada taraf signifikan $95 \%$ dan $\alpha=0,05$ diperoleh $\mathrm{U}_{\text {tab }}=1$, sedangkan Uhit $=2$ yang diambil berdasarkan nilai hitung terkecil, maka Ha diterima karena Uhit > $\mathrm{U}_{\text {tab. }}$ Berarti $\mathrm{U}_{\text {hit }}>$ $\mathrm{U}_{\text {tab }}$ dengan demikian $\mathrm{H}_{0}$ ditolak $\mathrm{H}_{\mathrm{a}}$ diterima. Jadi dapat disimpulkan bahwa model pembelajaran direct instruction efektif dalam meningkatkan keterampilan tata boga membuat cokelat aneka bentuk bagi anak tunarungu kelas V di SLB Perwari Padang. Selanjutnya saran yang peneliti berikan dari penelitian ini adalah kepada sekolah dan guru yang memberikan layanan pendidikan kepada anak tunarungu salah satunya keterampilan vokasional untuk bekal anak setelah tamat sekolah, sehingga tujuan pembelajaran dapat tercapai. Salah satunya menggunakan model pembelajaran direct instruction yang dapat menunjang proses pembelajaran. Peneliti berharap hasil penelitian ini dapat menambah wawasan serta ilmu pengetahuan yang luas lagi untuk peneliti selanjutnya serta lebih mengoptimalkan model pembelajaran direct instruction dan juga mengembangkan keterampilan tata boga lebih luas.

\section{Daftar Rujukan}

Arikunto, S. (2010). Prosedur Penelitian. Jakarta: Rineka Cipta.

\section{Arikunto, S. (2006). Prosedur Penelitian Suatu Pendekatan Praktik. Jakarta: PT Rineka Cipta}

Budi, S. S., \& Widyana, R. Korelasi Antara Kreativitas Belajar, Motivasi Belajar Dan Kemandirian Belajar Siswa Dengan Prestasi Belajar Keterampilan Elektronika Di Man I Wates Kabupaten Kulon Progo Tahun 2012. INSIGHT Volume 10, Nomor 1, Februari 2012

Hartaty, Y. (2017). Peningkatan Hasil Belajar Keterampilan Tata Boga Materi Pembuatan Brownis Pisang Melalui Model Pembelajaran Eksplicit Instruction. Iqra': Jurnal Kajian Ilmu Pendidikan, 2(1), 163-180Ishartiwi. (2010). 
Pembelajaran Keterampilan Untuk Pemberdayaan Kemandirian Anak Berkebutuhan Khusus. FIP UNY.

Ishartiwi, D. M. P. Pembelajaran Keterampilan Untuk Pemberdayaan Kemandirian Anak Berkebutuhan Khusus. UNY.

Mahardika, I. G. N. A. W. (2017). Teaching Hinduism For The Blinds: A Study On Hinduism Teaching And Learning In SLB A Negeri Denpasar. Vidyottama Sanatana: International Journal of Hindu Science and Religious Studies, 1(1), 70-76.

Marlina, M. (2014). Keterampilan Sosial Anak Berkesulitan Belajar Di Sekolah Dasar Inklusif. Penelitian Pendidikan, $5(1)$.

Moh, Nazir. (2009). Metode Penelitian. Jakarta: Ghalia Indonesia.

Rosilawati, I. (2013). Aneka Kreasi dan Tips Dunia Boga. Jakarta: Rama Edukasitama.

Sugiyono. (2009). Metode Penelitian Pendidikan. Jakarta: Alfabeta 